\title{
Using Anti-Müllerian Hormone and Serum Estradiol to Predict Ovarian Hyperstimulation Syndrome in Patients Using Antagonist Original Protocol During IVF/ICSI Cycles
} Article

\author{
Ahmed Kamel
}

Obstetrics and Gynecology Department, Cairo University, Cairo, Egypt.

\begin{abstract}
Objectives: To investigate the ability of Anti-Müllerian hormone (AMH) and estradiol (E2) to predict OHSS in women using the GnRH antagonist protocol while undergoing invitro-fertilization (IVF) or intra-cytoplasmic sperm injection (ICSI).

Study design: Retrospective analysis of women who had performed IVF/ICSI at assisted conception unit of Kasr Alainy university hospital over a period of 3 years.

Patients and Methods: Basal serum AMH, estradiol (E2) level on the day of ovulation trigger and OHSS, among various other parameters were recorded and analyzed.

Results: Thirty cases of OHSS (8.54\%) were identified. There was no statistical difference in incidence of OHSS among age $(p=0.976)$, FSH $(p=0.286)$, LH $(p=0.932)$, TSH $(p=0.277)$, and prolactin $(p=0.283)$, however, AMH $(p=0.04)$, BMI $(p=0.012)$, AFC $(p<0.001)$, and $\mathrm{E} 2$ before trigger $(p<0.001)$ were significant. The overall clinical pregnancy rate was $27.35 \%(\mathrm{n}=96)$. The receiver operator analysis curve had a cut-off value of $4.45 \mathrm{ng} / \mathrm{ml}(80 \%$, sensitivity \& $56 \%$ specificity). The area under the curve (AUC) was 0.661 with $95 \%$ confidence interval (CI) $(0.548-0.775)(p=0.003)$. While for E2 the cut-off value was $4459 \mathrm{pg} / \mathrm{ml}$ with $76.7 \%$ sensitivity and $55.7 \%$ specificity), AUC $0.67395 \%$ (CI) (0.554-0.791) ( $p=0.002)$. Combining both $\mathrm{AMH} \geq 4.45 \mathrm{ng} / \mathrm{ml}$ and $\mathrm{E} 2 \geq 4459 \mathrm{pg} / \mathrm{ml}$ had odds ratio $4.302(95 \% \mathrm{CI})(1.795$ 10.304), relative risk (RR) 0.891 with $95 \% \mathrm{CI}(0.832-0.954)(p<0.001)$.

Conclusion: AMH and serum E2 before trigger are not highly accurate tests alone for the prediction of OHSS. When basal serum AMH was $\geq 4.45 \mathrm{ng} / \mathrm{ml}$ and E2 $\geq 4459 \mathrm{pg} / \mathrm{ml}$, the patient was at 4 fold increased risk of developing OHSS.
\end{abstract}

Key Words: anti-mullerian hormone (Amh), estradiol (E2), intra-cytoplasmic sperm injection (ICSI), invitro fertilization (IVF); ovarian hyperstimulation syndrome (OHSS)

Revised: 24 November 2016, Accepted: 1 February 2017

Corresponding Author: Ahmed Kamel, MD., Obstetrics and Gynecology Department, Cairo University, Cairo, Egypt, E-mail: dr.ahmed.m.kamel@gmail.com

ISSN: 2090-7265, May 2017, Vol. 7, No. 2

\section{INTRODUCTION}

Ovarian hyperstimulation syndrome (OHSS) is a complication of ovulation induction treatment in assisted reproductive technologies (ART). This iatrogenic complication maybe life threatening, and is characterized by ovarian enlargement, abdominal distention and ascites. In addition to the aforementioned criteria severe cases may suffer from pleural effusion, electrolyte imbalance, oliguria, hemoconcentration and thromboembolism ${ }^{1}$.

While OHSS may occur spontaneously in ART, it has been linked to super-ovulation stimulation cycles with moderate to severe forms ranging from 3-10\%, and may reach as high as $20 \%$ in the high risk groups ${ }^{2}$. The incidence of hospitalization is $1.8 \%$ and the mortality rate is low with an estimated incidence at 1:400 000 to $1: 500000^{3,4}$.
OHSS is more common in younger ages and women in which the response is expected to be exaggerated during treatment e.g. polycystic ovarian syndrome (PCOS). It is also more common in cycles where clinical pregnancy occurred, and where human chorionic gonadotropins (hCG) used for ovulation trigger and luteal support ${ }^{5}$.

The etiology of OHSS remains unknown and is a subject of great controversy. The prediction of OHSS cycles is very difficult given its unknown etiology; however E2 levels during the stimulation cycle and the number of follicles have been studied with no prevail ${ }^{1}$. The Gonadotropin releasing hormone $(\mathrm{GnRH})$ antagonist protocol had offered advantages over the GnRH agonist protocol in the prevention of OHSS. This included using Gonadotropin releasing hormone agonist $(\mathrm{GnRHa})$ trigger, instead of an hCG trigger ${ }^{6}$. 
Basal levels of AMH shown to be a good OHSSpredictive with high sensitivity and specificity ${ }^{7,8}$

In the current study, we aimed to investigate the ability of AMH and E2 to predict OHSS in women using the $\mathrm{GnRH}$ antagonist protocol while undergoing in-vitro fertilization (IVF) or intra-cytoplasmic sperm injection (ICSI)

\section{PATIENTS AND METHODS}

This retrospective analysis was conducted on patients who had performed IVF/ICSI at assisted conception unit of Kasr Alainy university hospital in the period from January 2013 and January 2016. The study protocol was approved by the ethical committee. Besides, informed consents obtained from all of our patients to use their clinical data for scientific research.

The age of the women ranged from 20 -38 years, underwent IVF/ICSI. The gonadotropin $(\mathrm{GnRh})$ antagonist protocol was used for ovulation induction.

Patients were excluded from the study if they had an AMH level $<1 \mathrm{ng} / \mathrm{ml}$, antral follicle count $(\mathrm{AFC})<14$, or had a prolactin or thyroid abnormality.

Data concerning age, BMI, basal serum follicle stimulating hormone (FSH), luteinizing hormone (LH), AFC, basal serum AMH, estradiol (E2) level on the day of ovulation trigger, primary or secondary infertility, type of trigger, whether or not coasting was done, number of oocytes retrieved, number of embryos transferred, whether or not fresh embryo transfer was done (ET) and clinical pregnancy were all recorded.

In our center, the ovulation triggers included either human chorionic gonadotropin (hCG) 10000 IU (Choriomon, IBSA, Institut Biochimique SA) or triptorelin 0.1 S.C (Decapeptil®, Ferring Pharmaceuticals).

Coasting was considered done when HMG was withheld $\geq 1$ day before ovulation trigger. OHSS was recorded when a case underwent transvaginal aspiration of ascitic fluid at least once, which included moderate to severe forms of OHSS requiring intervention. We were not interested in milder forms, as most mild forms are treated conservatively in the outpatient clinic, which made it difficult to extract from retrospective data.

Data was statistically described in terms of mean \pm standard deviation $( \pm \mathrm{SD})$, or frequencies (number of cases) and percentages when appropriate. Comparison of numerical variables was done using Student $t$ test. Chi-square test was used to compare categorical data. Receiver operating characteristic (ROC) curve was used to determine a cut-off value for predicting an OHSS event requiring ascitic tapping. A two-tailed $\mathrm{P}$ value $<0.05$ was considered statistically significant. All statistical calculations were done using computer program SPSS (Statistical Package for the Social Science; SPSS Inc., Chicago, IL, USA) release 20 for Microsoft Windows (2006).

\section{RESULTS}

A total of 351 cases met the inclusion criteria. Thirty cases of OHSS $(8.54 \%)$ were identified in that time period, all of which required trans-vaginal tapping of ascitic fluid. Table-1 shows some of the population characteristics included in the data analysis between the groups that experienced OHSS compared to those that didn't. There was no statistical difference in age $(p=0.976)$, FSH $(p=0.286)$, LH $(p=0.932)$, TSH $(p=0.277)$, and prolactin $(p=0.283)$. However, a statistically significant difference was revealed between the two groups in the level of AMH $(p=0.04)$, $\mathrm{BMI}(p=0.012), \mathrm{AFC}(p<0.001)$ and $\mathrm{E} 2$ before trigger $(p<0.001)$

Table 2 shows the difference in some of the clinical variables between the studied groups. There was no statistical difference in the type of infertility $(p=0.464)$, number of oocytes retrieved $(p=0.09)$, number of embryos transferred $(p=0.879)$. The overall clinical pregnancy rate was $27.35 \%(\mathrm{n}=96)$, in the OHSS group was $16.7 \%(n=5)$ and $28.3 \%(n=91)$ in the non OHSS group ( $p=0.170)$. None of the cases with OHSS had a GnRh agonist trigger $(p=0.01)$, or had all their embryos frozen in the fresh transfer cycle $(p=0.039)$. All of the women with OHSS had hCG trigger that was statistically significant $(p=0.01)$.

A receiver operator analysis curve was used to determine the value of AMH in predicting an OHSS event requiring ascitic tapping. The cut-off value was $4.45 \mathrm{ng} / \mathrm{ml}$ with a sensitivity of $80 \%$, and a specificity of $56 \%$. The area under the curve was $0.66195 \%$ confidence interval (CI) (0.5480.775-) this is shown in (Fig. 1). Although, the value of AUC was statistically significant $(p=0.003)$, it corresponds to a poor test. While (Fig. 2) shows another ROC curve for the ability of Estradiol before trigger to predict an OHSS event requiring ascitic tapping. The cut-off value was $4459 \mathrm{pg} / \mathrm{ml}$ with a sensitivity of $76.7 \%$ and a specificity of $55.7 \%$. The area under the curve was $0.67395 \%$ (CI) (0.554-0.791). The value of AUC was also statistically significant $(p=0.002)$ but nevertheless corresponding to a poor test. The cut-off values for the ROC curve analysis were chosen to optimize both sensitivity and specificity in both graphs.

Table 3 shows the value of combining both $\mathrm{AMH} \geq$ $4.45 \mathrm{ng} / \mathrm{ml}$ and E2 $\geq 4459 \mathrm{pg} / \mathrm{ml}$. The calculated odds ratio was $4.30295 \% \mathrm{CI}(1.795-10.304)$, and a relative risk (RR) $0.89195 \% \mathrm{CI}(0.832-0.954)$ for developing an OHSS event requiring ascitic tapping when both these conditions are 
satisfied. Subsequently, cases with both $\mathrm{AMH} \geq 4.45 \mathrm{ng} /$ $\mathrm{ml}$ and $\mathrm{E} 2 \geq 4459 \mathrm{pg} / \mathrm{ml}$ are 4 times at risk of developing

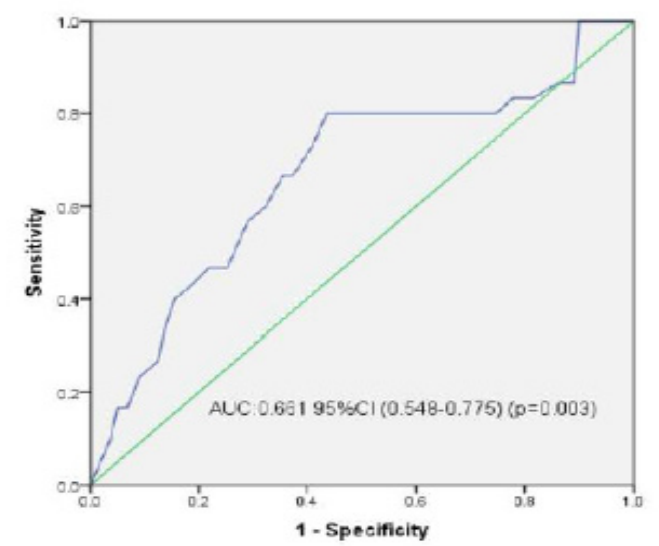

Fig. 1: Ability of AMH to predict OHSS.

Table 1: Population characteristics and hormone levels between cases with OHSS and those without OHSS.

\begin{tabular}{lccc}
\hline & $\begin{array}{c}\text { OHSS Requiring } \\
\text { Tapping }\end{array}$ & No OHSS & $P$ value \\
\hline Number (n) & 30 & 321 & - \\
Age (years) & $29.89 \pm 3.45$ & $30.02 \pm 3.19$ & 0.976 \\
$\begin{array}{l}\text { BMI (kg/ } \\
\text { m2) }\end{array}$ & $25.67 \pm 3.12$ & $30.89 \pm 11.28$ & $0.012^{*}$ \\
$\begin{array}{l}\text { FSH } \quad(I U / \\
\text { ml) }\end{array}$ & $5.27 \pm 1.73$ & $5.57 \pm 1.46$ & 0.286 \\
$\begin{array}{l}\text { LH (IU/ml) } \\
\text { AFC (n) }\end{array}$ & $6.51 \pm 1.93$ & $6.47 \pm 1.97$ & 0.932 \\
$\begin{array}{l}\text { AMH (ng/ } \\
\text { ml) }\end{array}$ & $4.87 \pm 1.1$ & $4.32 \pm 0.98$ & $0.04^{*}$ \\
$\begin{array}{l}\text { E2 before } \\
\text { trigger } \\
\text { (pg/ml) }\end{array}$ & $5520.5 \pm 1561.5$ & $4314.9 \pm 935.7$ & $<0.001^{*}$ \\
\hline$*$ Stati & & $20.98 \pm 2.51$ & $<0.001^{*}$ \\
\hline
\end{tabular}

*Statistically significant.
OHSS requiring intervention compared to other women who do not meet these criteria.

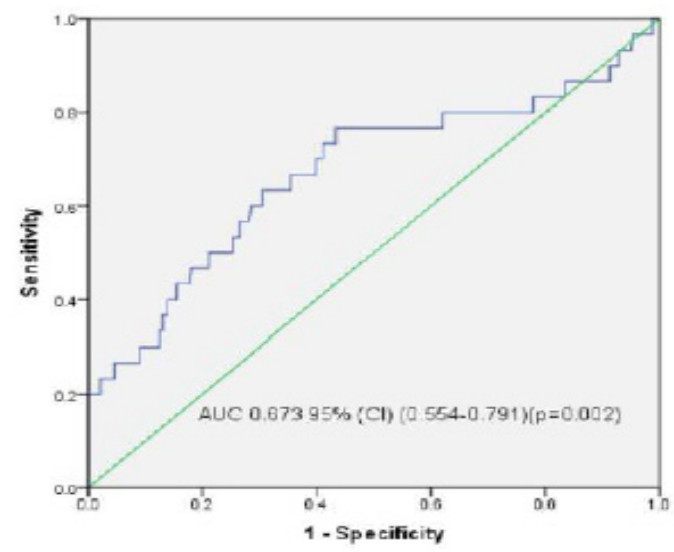

Fig. 2: Ability of E2 before trigger to predict OHSS.

Table 2: Comparison of clinical aspects of cycles in relation to OHSS

\begin{tabular}{|c|c|c|c|}
\hline & $\begin{array}{c}\text { OHSS } \\
\text { Requiring } \\
\text { Tapping } \\
\end{array}$ & No OHSS & $P$ value \\
\hline Number (n) & 30 & 321 & - \\
\hline $\begin{array}{l}\text { Type of infertility } \\
\mathrm{n}(\%)\end{array}$ & $\begin{array}{l}\text { Primary: } \\
21(70 \%) \\
\text { Secondary: } \\
9(30 \%)\end{array}$ & $\begin{array}{l}\text { Primary: } \\
244(76 \%)\end{array}$ & 0.464 \\
\hline Coasting & $16(53.3 \%)$ & $\begin{array}{l}\text { Secondary: } \\
77(24 \%)\end{array}$ & 0.533 \\
\hline hCG trigger & $30(100 \%)$ & $190(59.2 \%)$ & $0.01^{*}$ \\
\hline $\begin{array}{l}\text { GnRHa trigger } \\
\text { trigger }\end{array}$ & none & $262(81.6 \%)$ & $0.01^{*}$ \\
\hline $\begin{array}{l}\text { Freeze all } \\
\text { embryos/no fresh } \\
\text { transfer } n(\%)\end{array}$ & none & $59(18.4 \%)$ & $0.039^{*}$ \\
\hline $\begin{array}{l}\text { Number of oocytes } \\
\text { retrieved (n) }\end{array}$ & $17.12 \pm 4.14$ & $14.89 \pm 4.32$ & 0.09 \\
\hline $\begin{array}{l}\text { Number of } \\
\text { embryos } \\
\text { transferred (n) }\end{array}$ & $3.53 \pm 1.05$ & $3.02 \pm 1.17$ & 0.879 \\
\hline $\begin{array}{l}\text { Clinical } \\
\text { pregnancy n (\%) }\end{array}$ & $5(16.7 \%)$ & $91(28.3 \%)$ & 0.170 \\
\hline
\end{tabular}

Table 3: Odds and risk ratios for OHSS.

\begin{tabular}{|c|c|c|c|c|}
\hline & Number & Odds ratio & Risk ratio & $P$ value \\
\hline $\begin{array}{l}\text { AMH }>=4.45 \mathrm{ng} / \mathrm{ml} \& \text { E2_before_trigger }>=4459 \\
\mathrm{pg} / \mathrm{ml}\end{array}$ & $23(76.7 \%)$ & $4.302(1.795-10.304)$ & $\begin{array}{l}0.891(0.832- \\
0.954)\end{array}$ & $<0.001^{*}$ \\
\hline
\end{tabular}

Values are given as $\mathrm{n}(\%)$ or ratio $(95 \% \mathrm{CI})$.

*Statistically significant 


\section{DISCUSSION}

The main problem with measures preventing OHSS is the difficulty in predicting OHSS in individualized treatment cycles. A number of patient characters and basal ovarian reserve parameters have been investigated for their ability to predict OHSS with controversy among results. The prevention of OHSS is a multi-step process, and its main goal is identifying the risk factors and tailoring the induction protocol appropriately according to ovarian response during IVF/ICSI cycle ${ }^{9,10}$.

Although a higher basal serum AMH and E2 levels before trigger were statistically significant finding in the OHSS group as shown by the results; a cut-off value of $4.45 \mathrm{ng} / \mathrm{ml}$ for $\mathrm{AMH}$ while sensitive for predicting OHSS (80\%), the accuracy of the test appears poor $66 \%$ (as illustrated by the area under the curve). Similarly a cut-off value of $4450 \mathrm{pg} / \mathrm{ml}$ had a sensitivity of $76.7 \%$ but AUC was also in the range of $67 \%$. Among the most important findings was the 4 fold increased odds ratio for the development of OHSS when AMH level was 4.45ng/ $\mathrm{ml}$ and $\mathrm{E} 2 \geq 4459 \mathrm{pg} / \mathrm{ml}$.

The use of basal serum AMH before ovarian stimulation has been described for the prediction of OHSS. Two large randomized trials revealed that AMH is highly predictive of OHSS. A cut-off value of AMH levels $\sim \geq 3.5 \mathrm{ng} / \mathrm{ml}$ had high sensitivities and specificities $^{11,12}$. Lee et al. demonstrated that basal AMH and serum E2 on the day of trigger are reliable predictors of OHSS with AMH cut-off value of $>3.36 \mathrm{ng} / \mathrm{mL}$, with sensitivity of $90.5 \%$ and specificity of $81.3 \%$. The odds ratio for $\mathrm{AMH}$ alone was $1.7856,(P=0.0003)$ and for $\mathrm{E} 2$ was $1.0005,(P=0.0455)$.

No precise cut-off level for E2 during stimulation has been agreed upon by consensus ${ }^{5}$. Normally, a high or rapidly rising E2 on the day of trigger is a predictor of $\mathrm{OHSS}^{13}$. However, other studies revealed that high serum level of E2 alone is a poor predictor of OHSS ${ }^{13-15}$.

In this study, coasting was not a significant finding in the development of OHSS and none of the cases that developed OHSS had GnRHa trigger, or had all their embryos frozen (no fresh ET). A Cochrane review suggested that coasting had no benefit in regards to the development OHSS which was in agreement with our results ${ }^{16}$. On the contrary, some researchers found that coasting decreases the incidence of OHSS for women at risk $^{15-19}$

None of our cases that developed OHSS had a GnRHa-trigger, consistent with the studies by Decleer et $a l^{20}$ and Humaidan et $a l^{21}$ and Kol et $a l^{22}$. Griesinger et $a l^{23}$ obtained a reduced incidence of mild and moderate OHSS using a GnRHa-trigger, and only one cases out of 1924 women had an OHSS event.
Cryopreservation of all the embryos has been a strategy employed to reduce the risk of OHSS by resolving early OHSS and preventing late onset OHSS which is pregnancy related. In this study, no incidence of OHSS was obtained with the "freeze all" policy. This technique has proven effective in reducing but not completely eliminating the risk of OHSS without affecting the pregnancy rate ${ }^{24-28}$. In the Netherlands, a retrospective review of deaths related to IVF revealed three women died after cryopreservation of all embryos due to severe early-onset $\mathrm{OHSS}^{29}$.

BMI was significantly lower in the OHSS group. Other Studies investigated the value of low BMI (low body weight) in the prediction of OHSS with reported contradictory results. Currently BMI is not a useful marker for prediction of OHSS ${ }^{11,30}$. Similarly AFC while significant in the OHSS group, no cut-off value could be obtained (non-significant ROC analysis). Kwee et $a l$, obtained a cut-off value of AFC $>14$ with sensitivity $(82 \%)$ and specificity (89\%) for predicting ovarian hyper response ${ }^{31}$. This value for AFC while predicts hyper response, it can be hardly used in clinical application as it would mean all patients with normal AFC or higher are eligible for OHSS.

\section{Limitations of the study}

Limitation of this work included its retrospective nature, besides, non-reporting of the mild and moderate forms of OHSS, which didn't require tapping. Thus, they were difficult to extrapolate from, retrospective data.

Since, AMH and E2 levels may have been analyzed in different labs, sotheir standardization couldn't be done. Patients with predicted normal response to ovarian hyper-stimulation were not assessed, as all the women included in the analysis were already at higher risk for OHSS (as shown by high mean AMH, AFC) and they were prescribed antagonist protocol accordingly.

Furthermore, PCOS could not be analyzed as a risk factor for OHSS from retrospective data, as the data for its diagnostic criteria may be missing from the patient files (androgen profile).

\section{CONCLUSION}

Although AMH and serum E2 before trigger are significant factors in the prediction of OHSS, they are not highly accurate tests alone for its prediction. When basal serum AMH was $\geq 4.45 \mathrm{ng} / \mathrm{ml}$ and E2 $\geq$ $4459 \mathrm{pg} / \mathrm{ml}$ the patient was at 4 fold increased risk of developing OHSS. Randomized controlled studies are recommended to assess the value of these parameters and develop other test to predict OHSS. 


\section{Declaration of interest:}

The author of this study declares no conflict of interest and no competing interests with respect to the research, authorship, and publication of this article.

\section{Funding:}

This research did not receive any specific grant from any funding agency in the public, commercial or not-forprofit sector.

\section{REFERENCES}

1. Xing W, Lin H, Li Y, Yang D, Wang W, Zhang Q. Is the GnRH Antagonist Protocol Effective at Preventing OHSS for Potentially High Responders Undergoing IVF/ICSI? PLoS One 2015; 10(10): e0140286.

2. Nastri CO, Teixeira DM, Moroni RM, Leitão VM, Martins WP. Ovarian hyperstimulation syndrome: pathophysiology, staging, prediction and prevention. Ultrasound Obstet Gynecol. 2015; 45(4): 377- 393.

3. Brinsden PR, Wada I, Tan SL, Balen A, Jacobs HS. Diagnosis, prevention and management of ovarian hyperstimulation syndrome. Br J Obstet Gynaecol 1995; 102(10):767-772.

4. Mocanu E, Redmond ML, Hennelly B, Collins C, Harrison R. Odds of ovarian hyperstimulation syndrome (OHSS) - time for reassessment. Hum Fertil (Camb) 2007; 10(3): 175-181.

5. Mathur R, Evbuomwan I, Julian Jenkins J. Prevention and management of ovarian hyperstimulation syndrome. Current Obstetrics \& Gynaecology 2005; 15(2): 132-138.

6. Humaidan P, Kol S, Papanikolaou EG, Copenhagen GnRH Agonist Triggering Workshop Group. GnRH agonist for triggering of final oocyte maturation: Time for a change of practice? Hum Reprod Update 2011; 17(4): 510-524.

7. La Marca A, Sighinolfi G, Radi D, Argento C, Baraldi E, Artenisio AC, et al. Anti-Mullerian Hormone (AMH) as a predictive marker in Assisted Reproductive Technology (ART). Hum Reprod Update 2010; 16(2): 113-130.

8. Nardo LG, Gelbaya TA, Wilkinson H, Roberts SA, Yates A, Pemberton P, et al. Circulating basal antiMüllerian hormone levels as predictor of ovarian response in women undergoing ovarian stimulation for in vitro fertilization. Fertil Steril 2009; 92(5): $1586-1593$.
9. La Marca A, Sighinolfi G, Radi D, Argento C, Baraldi E, Artenisio AC, et al. Anti-Mullerian Hormone (AMH) as a predictive marker in Assisted Reproductive Technology (ART). Hum Reprod Update 2010, 16(2): 113-130.

10. Bosch E, Ezcurra D: Individualised controlled ovarian stimulation (iCOS): maximising success rates for assisted reproductive technology patients. Reprod Biol Endocrinol 2011; 9: 82.

11. Lee TH, Liu CH, Huang CC, Wu YL, Shih YT, Ho $\mathrm{HN}$, et al. Serum anti-Müllerian hormone and estradiol levels as predictors of ovarian hyperstimulation syndrome in assisted reproduction technology cycles. Hum Reprod 2008; 23(1):160-167.

12. El-Halawaty S, Rizk A, Kamal M, Aboulhassan M, Al-Sawah H, Noah O, Al-InanyH.Clinical significance of serum concentration of anti-Müllerian hormone in obese women with polycystic ovary syndrome.Reprod Biomed Online. 2007 Nov;15(5):495 -9.

13. Papanikolaou EG, Humaidan P, Polyzos NP, Tarlatzis B. Identification of the high-risk patient for ovarian hyperstimulation syndrome. Semin Reprod Med 2010; 28(6): 458-462.

14. Humaidan P, Quartarolo J, Papanikolaou EG. Preventing ovarian hyperstimulation syndrome: guidance for the clinician. Fertil Steril 2010, 94(2) 389-400.

15. Alper MM, Smith LP, Sills ES. Ovarian hyperstimulation syndrome: Current views on pathophysiology, risk factors, prevention and management. J Exp Clin Assist Reprod 2009; 10: 3.

16. D'Angelo A, Brown J, Amso NN. Coasting (withholding gonadotrophins) for preventing ovarian hyperstimulation syndrome. Cochrane Database Syst Rev 2011; 6: CD002811.

17. Levinsohn-Tavor O, Friedler S, Schachter M, Raziel A, Strassburger D, Ron-El R. Coasting-what is the best formula? Hum Reprod 2003; 18(5): 937-940.

18. García-Velasco JA, Zúñiga A, Pacheco A, Gómez $\mathrm{R}$, Simón C, Remohí J, et al. Coasting acts through downregulation of VEGF gene expression and protein secretion. Hum Reprod 2004; 19(7): $1530-1538$.

19. Mansour R, Aboulghar M, Serour G, Amin Y, Abou-Setta AM. Criteria of a successful coasting 
protocol for the prevention of severe ovarian hyperstimulation syndrome. Hum Reprod 2005; 20(11): 3167-3172.

20. Decleer W, Osmanagaoglu K, Seynhave B, Kolibianakis S, Tarlatzis B, Devroey P. Comparison of hCG triggering versus hCG in combination with a GnRH agonist: A prospective randomized controlled trial. Facts Views Vis Obgyn 2014; 6(4): 203209-.

21. Youssef MA, van Wely M, Al-Inany H, Madani T, Jahangiri N, Khodabakhshi S, Alhalabi M, Akhondi M, Ansaripour S, Tokhmechy R, Zarandi L, Rizk A, El-Mohamedy M, Shaeer E, Khattab M, Mochtar MH, van der Veen F.A mild ovarian stimulation strategy in women with poor ovarian reserve undergoing IVF: a multicenter randomized non-inferiority trial.Hum Reprod. 2017 Jan;32(1):112- 118.

22. Kol S, Solt I. GnRH agonist for triggering final oocyte matura- tion in patients at risk of ovarian hyperstimulation syndrome: Still a controversy?. J Assist Reprod Genet 2008; 25(2- 3) 63- 66.

23. Griesinger G, Diedrich K, Devroey P, Kolibianakis EM. GnRH agonist for triggering final oocyte maturation in the GnRH antagonist ovarian hyperstimulation protocol: A systematic review and meta-analysis. Hum Reprod Update 2006; 12(2): $159-168$.

24. Sills ES, McLoughlin LJ, Genton MG, Walsh DJ, Coull GD, Walsh AP. Ovarian hyperstimulation syndrome and prophylactic human embryo cryopreservation: Analysis of reproductive outcome following thawed embryo transfer. J Ovarian Res 2008; $1: 7$.
25. Fitzmaurice GJ, Boylan C, McClure N. Are pregnancy rates compromised following embryo freezing to prevent OHSS? Ulster Med J 2008; 77(3): 164-167.

26. Gera PS, Tatpati LL, Allemand MC, Wentworth MA, Coddington CC. Ovarian hyperstimulation syndrome: Steps to maximize success and minimize effect for assisted reproductive outcome. Fertil Steril 2010; 94(1): 173-178.

27. Queenan JT Jr, Veeck LL, Toner JP, Oehninger S, Muasher SJ. Cryopreservation of all prezygotes in patients at risk of severe hyperstimulation does not eliminate the syndrome, but the chances of pregnancy are excellent with subsequent frozen-thaw transfers. Hum Reprod 1997; 12(7): 1573-1576.

28. Ferraretti AP, Gianaroli L, Magli C, Fortini D, Selman HA, Feliciani E. Elective cryopreservation of all pronucleate embryos in women at risk of ovarian hyperstimulation syndrome: Efficiency and safety. Hum Reprod 1999; 14(6): 1457-1460.

29. Braat DD, Schutte JM, Bernardus RE, Mooij TM, van Leeuwen FE. Maternal death related to IVF in the Netherlands 1984-2008. Hum Reprod 2010; 25(7): 1782-1786.

30. Delvigne A, Rozenberg S. Epidemiology and prevention of ovarian hyperstimulation syndrome (OHSS): A review. Hum Reprod 2002; 8(6): 559-577.

31. Kwee J, Elting ME, Schats R, McDonnell J, Lambalk CB. Ovarian volume and antral follicle count for the prediction of low and hyper responders with in vitro fertilization. Reprod Biol Endocrinol 2007; 5: 9 . 